\title{
Kızılcaören (Sivrihisar) Bölgesi Nadir Toprak Element (NTE) İçeren Minerallerin Mineral Serbestleşme Analiz (MLA) Yöntemi Kullanılarak Tayini
}

\author{
Nihal Yeşilören-Görmüşş ${ }^{1 *}$, Gökçe Gürtekin ${ }^{1}$, Ayşe Erdem ${ }^{2}$, Akan Gülmez ${ }^{3}$ \\ ${ }^{1}$ MTA Genel Müdürlüğ̈̈, Maden Analizleri ve Teknolojisi Dairesi Başkanlı̆̆l, Mineraloji Petrografi Araştırmaları \\ Koordinatörlüğ̈̈, Ankara, Türkiye \\ ${ }^{2}$ MTA Genel Müdürlüğ̈̈, Maden Analizleri ve Teknolojisi Dairesi Başkanlı̆̆g, Ankara, Türkiye. \\ ${ }^{3}$ MTA Genel Müdürlüğü, Ankara, Türkiye \\ *nihal.gormus@mta.gov.tr ${ }^{\mathbb{D}}$,gokce.gurtekin@mta.gov.tr ${ }^{\mathbb{D}}$, ayse.erdem@mta.gov.tr@, akan.gulmez@mta.gov.tr@ \\ Makale gönderme tarihi: 31.03.2021, Makale kabul tarihi: 17.06.2021
}

\begin{abstract}
$\ddot{O} \mathbf{z}$
Nadir Toprak Element (NTE) yataklarının çoğu, karmaşık jeolojik süreçler nedeniyle farklı tektonik ortamlarda oluşmuştur. $\mathrm{Bu}$ durum, benzer kimyasal bileşime sahip çeşitli NTE minerallerinin oluşmasına neden olmaktadır. Petrografi, X-ışını kırınımı (XRD) ve tüm kayaç jeokimyası gibi geleneksel tanımlama ve analiz yöntemlerini uygulayarak NTE minerallerini sınıflandırmak son derece zordur. Bu nedenle, mineralojik karakterizasyon çalışmaları sırasında NTE minerallerinin kimyasal bileşimlerini belirlemeye yönelik gelişmiș analiz sistemleri kullanılmalıdır. Bu çalışmada, Kızılcaören Ba-F-NTE yatağından alınan NTE mineralleri, mineral serbestleşme analizi (MLA) sistemi kullanılarak tanımlanmıştır. Bu çalışmalar sonucunda, bölgede bulunan NTE mineralleri, kimyasal bileşimleri (Ca, NTE, F, P) dikkate alınarak sınıflandırılmış olup, çoktan aza doğru Th içeren parazit-(Ce), NTE karbonat, sinçisit-(Ce) ve monazitten oluşmaktadır.
\end{abstract}

Anahtar Sözcükler: Kantitatif mineraloji, Kızılcaören (Sivrihisar), mineral serbestleşme analizi (MLA), nadir toprak element (NTE), toryum (Th), parisit

\section{Determination of Minerals Containing Rare Earth Elements (REE) in Kızılcaören (Sivrihisar) Region Using Mineral Liberation Analysis (MLA) Method}

\begin{abstract}
Most of Rare Earth Element (REE) deposits have been formed in different tectonic environments because of complex geological processes. This situation leads to the formation of various REE minerals with similar chemical compositions. It is extremely hard to classify REE minerals by performing conventional description and analysis methods such as petrography, X-ray diffraction (XRD) and whole rock geochemistry. Therefore, advanced analysis systems that are cabaple to determine chemical compositions of REE minerals must be used during the mineralogical characterization studies. In this study, the REE minerals from the Kizılcaören Ba-F-REE deposit have been identified by using mineral liberation analysis (MLA) system. As a result of these studies, the REE minerals in the region have been classified considering their chemical compositions (Ca, REE, F, P), and are composed of Th-bearing parasite-(Ce), REE carbonate, synchysite-(Ce) and monazite from high to low abundances, respectively.
\end{abstract}

Keywords: Quantitative mineralogy, Kızılcaören (Sivrihisar), mineral liberation analysis (MLA), rare earth element (REE), thorium (Th), parisite

\section{GíRiş}

Nadir Toprak Elementleri (NTE) kimyasal tabloda lantanit grubu olarak 15 adet element ile temsil

çizelgede geçiş metallerinin bir alt serisini edilmektedir. Lantanitler ve NTE, periyodik oluşturmaktadır. Bu grup elementleri, Atom numarası 57 olan lantanyum $(\mathrm{La})$ ile atom numaras 71 olan 
lutesyum $(\mathrm{Lu})$ arasındaki elementler oluşturmakta olup, atom numaras1 21 olan skandiyum $(\mathrm{Sc})$ ve atom numarası 39 olan itriyum (Y) da benzer kimyasal ve fiziksel özellikleri nedeniyle NTE grubuna dahil edilmektedir (Yıldız, 2016; Castor ve Hedrick, 2006). Böylece NTE'ler toplamda 17 adet elementten meydana gelmektedir.

NTE'ler, düşük atom ağırlıklarına sahip olup, La ve $\mathrm{Eu}$ arası elementlerden oluşan hafif nadir toprak elementler (HNTE); Gd-Lu arasi elementlerden oluşan ağır nadir toprak elementler (ANTE) şeklinde iki gruba ayrılmaktadır (Samson ve Wood, 2004). Bu elementler; halitler, karbonatlar, oksitler, fosfatlar ve silikatlar gibi çeşitli mineral grupları içerisindeki minerallerin bünyesine girebilir ve kayaç oluşturan minerallerin ana iyonları ile yer değiştirebilirler (Möller, 1986). Nadir toprak element içeren yaklaşık 200'e yakın mineral bulunmakta, ancak bunların sadece çok az bir kısmı ticari önem taşımaktadır. NTE cevherleşmeleri, çoğunlukla kompleks bir mineralojiye sahiptir. Bu kompleks bileşim, NTE içeren minerallerin, petrografik, XRD ve tüm kayaç kimyası gibi klasik analiz metotları ile saptanmasını zorlaştırmaktadır. $\mathrm{Bu}$ nedenle, minerallerin saptanmasında, kimyasal bileşimlerinin dikkate alındığı analiz metotlarının uygulanması gerekmektedir.

$\mathrm{Bu}$ çalışmada, Kızılcaören (Sivrihisar-Eskişehir) kompleks barit-florit-NTE cevherleşmesinde, taramalı elektron mikroskop (SEM) tabanlı otomatik analiz sistemi olan MLA kullanılarak, NTE içeren minerallerin tayini yapılmıştır.

\section{BÖLGENIN GENEL JEOLOJIK YAPISI}

Çalışma alanı, yapısal jeolojisi ve stratigrafisi, cevherleşme ve ilişkili kayaçlar ve mineral potansiyeline yönelik olarak detaylı jeolojik ve mineralojik araştırmalara konu olmuştur (Romieux, 1942; Kupfahl, 1954; Kaaden, 1966; Kulaksız, 1972; Erentöz, 1975; Bingöl, 1976; Uçmak, 1969; Kaplan, 1977; Yakabağı, 1977; Arda, 1976; Nakoman, 1979; Çağatay, 1981; Delaloye ve Özgenç, 1983; Kırıkoğlu, 1983; Özgenç, 1983; Stumpfl ve Kırıkoğlu, 1985; Özgenç, 1993; Gültekin ve Örgün, 2000; Gültekin vd., 2003; Şen vd., 2012; Nikiforov vd., 2014; Öztürk vd., 2019).
Kızılcaören barit-florit-NTE kompleks cevherleşmesi, İzmir-Ankara-Erzincan Kenet Kuşağı'nın kuzeyinde ve Paleotetis Okyanusu'nun çoğunlukla kabuk kaynaklı kayaçları (Sayit ve Göncüoğlu, 2009) ve yığışım birimlerini içeren Sakarya Kuşağı'nda Karakaya Kompleksi içinde yer almaktadır (Çimen vd., 2020).

Çalışma bölgesi içerisinde; Paleozoyik yaşlı metamorfik kayaçlar, Triyas yaşlı serpantinleşmiş ultrabazik kayaçlar, fillitler, fillitik şistler ve kısmen metamorfize olmuş sedimanter kayaçlar (metagrovak, metaarkoz, şeyl, çamurtaşı, kumtaşı), Jura yaşlı konglomera, kumtaşı ve Senozoik riftleşme ile ilişkili alkali volkanik kayaçlar bulunmaktadır. Bölgede bulunan barit-florit-NTE cevherleşmesi, Permiyen yaşlı kireçtaşı olistolitleri içeren Triyas yaşlı klastik kayaçlar ile Oligo-Miyosen yaşlı diyabazik dayk ve lavlardan oluşan kompleks seri içerisindedir. Cevher sahası, birçok fay sistemi ile kesilmiştir. Sözü edilen fay ve diğer kırık sistemleri, nadir toprak elementlerin yanı sira barit-florit cevher damarlarına ev sahipliği yapmıştır (Şekil 1) (Gültekin ve Örgün, 2000; Gültekin vd. 2003).

\section{Kızılcaören NTE Cevherleșmesi}

Türkiye'de bilinen en önemli nadir toprak cevherleşmesini oluşturan yatağa ilişkin 1960'lı yıllardan bu yana sürdürülen çalışmalar, biri hidrotermal diğeri karbonatitik olmak üzere iki farklı jenetik görüş ortaya çıkarmıştır.

Özgenç (1993), Geç Oligosen yaşlı magmatik faaliyetler sonucunda küçük dayklar şeklinde karbonatitlerin oluştuğunu ileri sürmüş ve breşleşme öncesi ve sonrası şeklinde iki farklı karbonatit fazı ayırt etmiştir. Araştırıcıya göre; breşleşme öncesi karbonatitler, başlıca florit ve barit mineralizasyonu ile karakteristiktir. NTE mineral fazlarına az miktarda rastlanılmakta olup, diğer mineralleri kalsit, dolomit, diyopsit, biyotit, manyetit, apatit, rutil, plajiyoklaz, filogopit, fluoserit, brokit, braunit, pirit, götit, kuvars ve Mn-oksitler oluşturmaktadır. Breşleşme sonrası karbonatitler ise, breşleşme öncesi karbonatitlerle benzer mineralojik bileşime sahip olup, NTE ve iz elementler açısından zenginleşmiş durumdadır. Görülen en yaygın NTE minerali torbastnazittir (Th içeren bastnazit). 


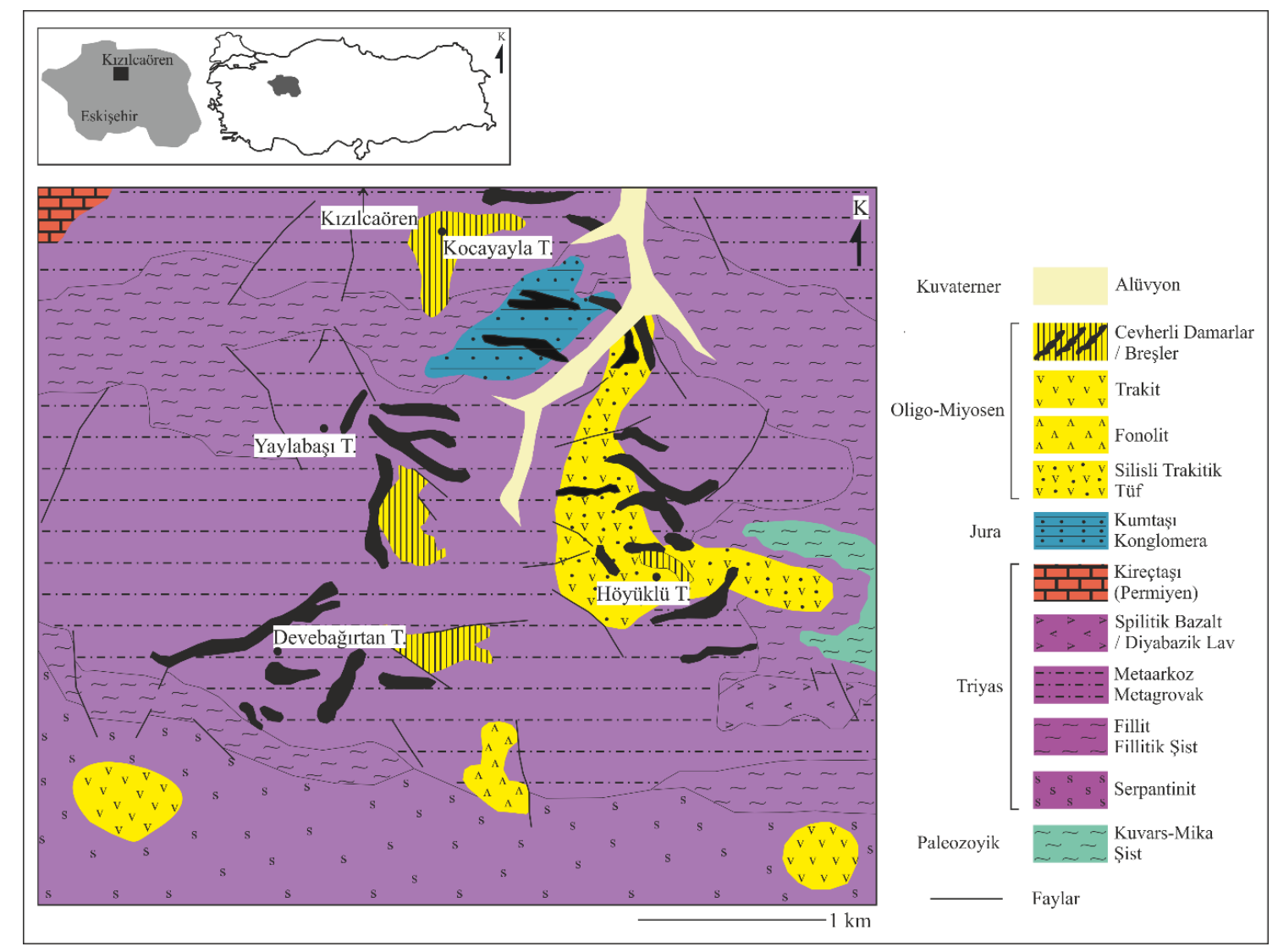

Şekil 1. Çalışma bölgesinin jeoloji haritası (Gültekin vd. 2003’ten değiştirilerek alınmıştır)

Nikiforov vd. (2014), büyük bir fay zonunda yer alan cevherin, subvolkanik kompleksin bir bileșeni olduğunu ifade etmiş, kompleksi fonolit-trakit stokları, karbonatit/karbonat-silikat daykları ve floritbarit-bastnazit cevherleşmesi olarak gruplandırmıştır. Florit-barit-bastnazit cevherleşmesi, büyük damarlar ve tektonik breş çimentosu şeklindedir. Bu toplam hacmin \%60-65'i florit ve baritten oluşurken, \%10'lara varan oranlarda da bastnazite rastlanılmaktadır. Araştırıcılar tarafından; karbonatit ve karbonat-silikatlar olarak adlandırılan kayaçlar, filogopit-kalsit karbonatitler ve filogopit-kalsit-albit karbonatitler şeklinde iki gruba ayrılmıştır. Filogopitkalsit karbonat kayaçları içerisinde, kalsit, filogopit, barit ve eser oranlarda apatit, Fe-Mn hidroksitler, piroklor ve HNTE florokarbonatlar saptanmıștır. Filogopit-kalsit-albit karbonatitlerde ise; albit, kalsit, filogopit, Fe oksit ve eser oranlarda barit, apatit, zirkon, piroklor ve tanımlanamamış NTE-iz element mineralleri saptanmıştır. HNTE florokarbonatlar; filogopit-kalsit karbonatitler ve fonolitler içerisinde tespit edilmiş olup, yaklaşık \%10 Th ve yaklaşık
\%5.6 Sr içermektedir. Minerallerin kimyasal bileşimlerinin yeniden hesaplanması sonucu NTE içeren karbonat grubu minerallerin bastnazit ve parisit bileşimleri arasında olduğu tespit edilmiştir. Filogopit-kalsit karbonatit içerisindeki HNTE florokarbonatlarını parisit oluşturmakta olup, bu grupta $\mathrm{Sr}$ yaklaşık \%1.6-1.8 değerleri arasında iken toryuma rastlanılmamıştır.

Gültekin ve Örgün (2000) ve Gültekin vd. (2003), sı̆̆ derinliklere kadar sokulmuş nötr-asidik magmalarla bağlantılı volkanizma ile ilişkili hidrotermal cevherleşmenin, yatağın oluşumunda etkin olduğunu ileri sürmüştür. Araştırıcılar, Kızılcaören barit-floritnadir toprak cevherleşmesini; Permiyen yaşl1 kireçtaşı olistolitleri içeren klastik kayaçlar ile diyabazik dayk ve lavlardan oluşan kompleks seri içerisindeki iri taneli damar dolguları, klastik kayaç parçalı tektonik breş cevheri ve mercek şekilli cevher kütleleri olmak üzere 3 farklı tipte sınıflandırmışlardır. Damar dolguları özellikle Kocadevebağırtan, Kocayayla, Yaylabaşı ve Küçükhöyüklü bölgelerindeki en yaygın cevher tipini 
oluşturmakta olup, tipik minerallerini, başlıca florit, barit, bastnazit, Mn-Oksit, fluoserit, psilomelan, piroluzit, kalsit, kuvars, pirit, monazit, brokit, hematit, götit, filogopit, ankerit, rutil, galenit, sfalerit ve kalkopirit oluşturmaktadır. Çalıșma sahasında, cevherin nispeten yüksek Th içeriğine karşın, yapılan mineralojik çalışmalarda herhangi bir Th içeren mineral saptanamamış, toryumun NTE minerallerinin kristal yapısında bulunduğu ifade edilmiştir (Özgenç, 1983; Kırıkoğlu, 1983).

\section{MATERYAL VE METOT Numune Alma}

$\mathrm{Bu}$ çalışmada, ETİ Maden İşletmeleri Genel Müdürlüğü tarafından 2014 yılında yapılmış olan, Devebağırtan sektörüne ait NTEM-2014/120 ve NTEM-2014/297 numaralı sondajlara ait karot örnekleri kullanılmıştır.

\section{Laboratuvar Çalışmaları}

Laboratuvar çalışmaları; XRD, kimyasal, elek analizi ve MLA analizlerini kapsamaktadır. Kimyasal analizler MTA Genel Müdürlüğü MAT Dairesi Başkanlığı Analiz Laboratuvarları Koordinatörlüğü, elek analizleri Teknoloji Koordinatörlüğü, mineralojik petrografik çalışmalar ve MLA analizleri ise Mineraloji-Petrografi Araştırmaları Koordinatörlüğü gerçekleştirilmiştir.

Alınan bütün örnekler, ilk olarak oda sicaklığında kurumaya bırakılmıştır. XRD, kimyasal ve MLA analizlerinde kullanılacak örnekler, çeyrekleme metodu ve döner numune bölücüler (rotary sample divider) kullanılarak çeyreklenmiş ve yapılacak analizlere uygun miktarlarda temsili numuneler hazırlanmıştır.

Mikroskobik çalışmalar, Leica DM 2500P marka/model polarize mikroskop ile yapılmıştır.

XRD analizlerinde, örnekler ilk olarak agat havanda uygun tane boyutuna $(30 \mu)$ gelene kadar öğütülmüştür. Öğütülen örneklerin tüm kayaç XRD çekimleri $4-70^{\circ}$ derece arasında, 0.03 adım aralığında ve $15 \%$ dk koşullarında gerçekleştirilmiş olup, XRD piklerinin değerlendirilmesinde Panalytical High Score Plus yazılımı ve Pan-ICSD kütüphanesi kullanılmıştır.

Örneklerin kimyasal bileşimlerini belirlenmek amaciyla, Thermo ARL marka/model XRF (X-1şını floresans) cihazı kullanılarak ana element analizleri yapılmıştır. Analizler öncesinde her örnek, \%85'i 75 $\mu$ 'nun altında olacak şekilde ögütülmüş ve yaklaşık $4.5 \mathrm{~g}$ temsili numuneler hazırlanmıştır. Numuneler, pellet (3.0 g örnek $+0.9 \mathrm{~g}$ selüloz karışımı) haline getirilerek analiz edilmiştir.

Örnekleri MLA analizlerine uygun hale getirmek için elek analizleri yapılmış olup, örnekler $-300+150 \mu$, $150+75 \mu,-75+38 \mu,-38+20 \mu$ ve $-20+10 \mu$ aralıklarında fraksiyonlarına ayrılmıştır.

Elek analizi ile ayrılmış bütün fraksiyonlar, Quantachrome marka döner mikro çeyrekleyici (rotary micro riffler) kullanılarak çeyreklenmiş ve MLA analizleri için gerekli olan 2 gram temsili örnekler hazırlanmıştır. MLA numuneleri hazırlanırken, $40 \mu$ 'dan küçük tanelerin birbirleri ile yapışarak topaklanma eğilimi göstermemeleri için $75+38 \mu$ altındaki örneklere, örnek ile yaklaşık eşit miktarlarda olacak şekilde saf grafit tozu eklenmiştir. Çeyreklenen ve grafit eklenen örnekler, soğuk kalıplama yöntemiyle kalıba alınarak, yüzeyleri Buehler PowerPro 4000 marka/model aşındırma parlatma makinesinde, toplam 7 aşamada aşındırılıp parlatılmıştır. Yüzeyleri parlatılmış örnekler, Leica EM ACE200 marka/model karbon kaplama makinesi kullanılarak kaplanmış ve MLA analizlerine hazır hale getirilmiştir.

Örneklerin modal mineralojik bileşimlerini, hesaplanmış elementel içeriklerini (Calculated Assay), elementel dağılımlarını (Elemental Distribution), minerallerin serbestlik ve kenetlilik durumları (Mineral Locking) ile parçacıklara ait fiziksel parametreleri belirlemek amaciyla MLA analizleri gerçekleştirilmiştir. MLA analizleri, Bruker X-Flash çift EDS (dual EDS) sisteme sahip FEI MLA 650 ve FEI Quanta 400 MLA cihazları kullanılarak yapılmıştır. Veri oluşturma, işleme ve görüntüleme işlemlerinde; MLA Suite 3,1 program paketi ve FEI Standart Reference, FEI Mineral Reference $20 \mathrm{kV}$ ve FEI Reference STD $25 \mathrm{kV}$ mineral kütüphaneleri kullanılmıştır.

MLA analizlerinde, mineral taneleri ve parçacıkları, BSE görüntüleri ve EDS spektrumları kullanılarak birbirlerinden ayırt edilmektedir. Bu çalışmadaki MLA analizleri, MLA program paketi içerisinde yer alan ölçüm (Measurement), mineral referans (Mineral Reference), görüntü işleme (Image Proccesing) ve veri oluşturma / görüntüleme (Data View) alt modülleri kullanılarak 4 aşamada gerçekleştirilmiştir (Şekil 2). 


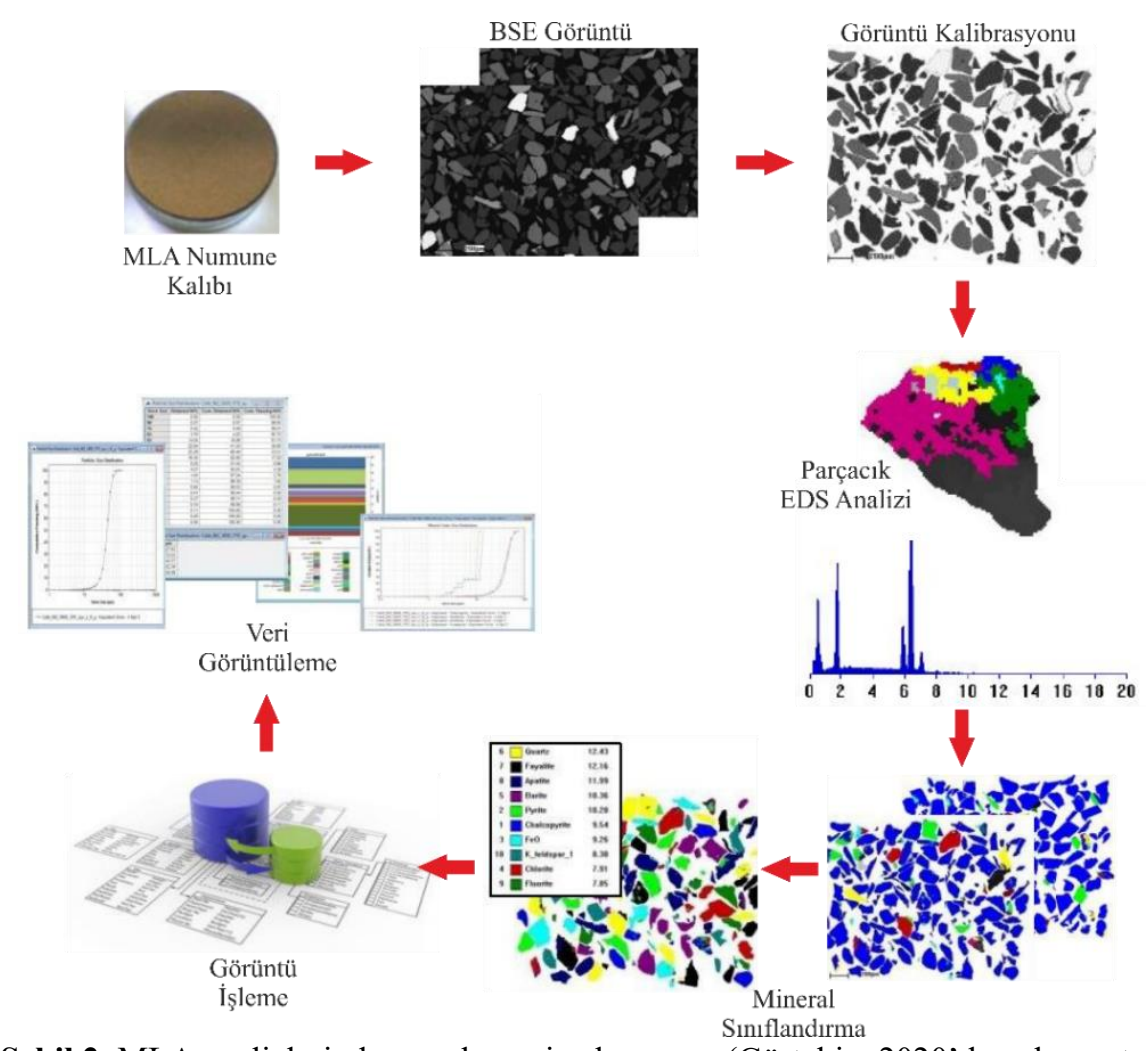

Şekil 2. MLA analizlerinde uygulanan iş-akış sırası (Gürtekin, 2020'den alınmıştır)

\section{ANALIZ VERILERININ DEĞERLENDİRILMESİ Mineraloji-Petrografi}

Yapılan mineralojik petrografik analizler sonucu örnekler, breşik kayaçlar, barit-florit zenginleşmesi ve daha az miktarda da metakumtaşları olarak sınıflandırılmıştır. Breşik kayaçlar kırıntılı dokulu olup, tamamen $\mathrm{Fe}$ ve/veya Mn oksitlere dönüşmüş, bu sebeple ilksel doku ve bileşimini kaybetmiş kayaç parçalarından; barit-florit zenginleşmeleri başlıca, barit, florit, kil grubu mineraller, biyotit ve muskovit mineralleri ile alterasyon ürünü $\mathrm{Fe}$ ve/veya $\mathrm{Mn}$ oksitlerden; metakumtaşları ise kırıntılı dokulu olup, plajiyoklaz grubu mineraller, ortoklaz, biyotit, muskovit ve altere kayaç parçalarından oluşmaktadır.

\section{X-ışııı Kırınımı (XRD)}

Kalitatif XRD analizi sonucu belirlenen ana mineraller, florit + barit + götit + mika grubu mineraller \pm kuvars \pm alkali feldispat \pm kalsit \pm dolomit \pm kil grubu minerallerdir. Çalışma bölgesindeki kompleks mineralojik bileşim ve yapı, NTE içeren minerallerin XRD difraktogramlarının çözümlenmesini zorlaştırmıştır. XRD analizi yapılan bazı örneklerde NTE mineralleri için kesin bir tanımlama yapılamamıştır.

\section{Kimyasal Analizler}

Alınan örneklerin, derinliğe bağlı ana element değerleri Tablo 1'de verilmiştir. 120B, 120D, 120E ve 297A kodlu örneklerdeki, Nadir Toprak Oksit (NTO: $\mathrm{La}_{2} \mathrm{O}_{3}, \mathrm{CeO}_{2}, \operatorname{Pr}_{6} \mathrm{O}_{11}, \mathrm{Nd}_{2} \mathrm{O}_{3}$ ) değerlerinin nispeten yüksek olduğu dikkat çekmektedir. $\mathrm{Bu}$ nedenle, NTO değerlerinin yüksek olduğu 120B, 120D, 120E ve 297A kodlu örneklerde MLA analizleri yapılmıştır.

\section{Mineral Serbestleşme Analizi (MLA)}

MLA sisteminin temel mantığı, BSE (geri saçılımlı elektronlar) görüntülerini ve EDS (enerji dağılımlı spektrometre) spektrumlarını kullanarak, örnek içerisindeki parçacıkların ve mineral tanelerinin sınırlarını belirleyerek birbirlerinden ayırt edilmelerine dayanmaktadır.

MLA analizleri modal mineralojik bileşim, hesaplanmış elementel içerik, elementel dağılım ve mineral serbestleşme alt başlıkları altında değerlendirilmiştir. 
Tablo 1. Örneklere ait ana oksit değerleri

\begin{tabular}{|c|c|c|c|c|c|c|c|c|c|}
\hline & \multicolumn{7}{|c|}{ NTEM-2014 / 120* } & \multicolumn{2}{|c|}{ NTEM-2014 / 297* } \\
\hline & $\begin{array}{c}120 \mathrm{~A} \\
7.2-11.1 \mathrm{~m}\end{array}$ & $\begin{array}{c}120 \mathrm{~B} \\
11.1-15 \mathrm{~m}\end{array}$ & $\begin{array}{c}120 \mathrm{C} \\
15-18.7 \mathrm{~m}\end{array}$ & $\begin{array}{c}120 D \\
18.7-20.5 \mathrm{~m}\end{array}$ & $\begin{array}{c}120 \mathrm{E} \\
22.7-24.5 \mathrm{~m}\end{array}$ & $\begin{array}{c}120 \mathrm{~F} \\
32-34.3 \mathrm{~m} \\
\end{array}$ & $\begin{array}{c}120 G \\
\text { 34.3-35.7 } \mathrm{m} \\
\end{array}$ & $\begin{array}{c}297 \mathrm{~A} \\
21.9-25.7 \mathrm{~m}\end{array}$ & $\begin{array}{c}297 B \\
37.6-41.3 \mathrm{~m} \\
\end{array}$ \\
\hline $\mathrm{CaF}_{2}$ & 11.8 & 22.3 & 13.4 & 22.3 & 30.9 & 10.7 & 17 & 24.5 & 15.1 \\
\hline $\mathrm{Na}_{2} \mathrm{O}$ & 0.7 & 0.3 & 0.3 & 0.3 & 0.3 & 0.3 & 0.4 & 0.2 & 0.2 \\
\hline MgO & 7.5 & 3.4 & 4.0 & 2.3 & 4.0 & 7.1 & 6.1 & 0.9 & 2.7 \\
\hline $\mathrm{Al}_{2} \mathrm{O}_{3}$ & 7.8 & 2.8 & 7.1 & 3 & 0.9 & 0.6 & 0.9 & 6.4 & 12.3 \\
\hline $\mathrm{SiO}_{2}$ & 34.1 & 11.6 & 25.8 & 11.7 & 17.8 & 58.5 & 31.4 & 19 & 37.9 \\
\hline $\mathbf{P}_{2} \mathbf{O}_{5}$ & 0.5 & 0.4 & 0.3 & 0.3 & 0.2 & 0.1 & 0.2 & 0.7 & 0.3 \\
\hline $\mathrm{SO}_{3}$ & 2.2 & 10.1 & 7.1 & 13.4 & 6.5 & 1.3 & 5.4 & 7.4 & 1.2 \\
\hline $\mathrm{BaO}$ & 5 & 21.1 & 15.2 & 25.9 & 12.9 & 2.4 & 10.8 & 15 & 2.6 \\
\hline $\mathrm{K}_{2} \mathrm{O}$ & 6.1 & 2.3 & 5.7 & 2.5 & 1.6 & 2.6 & 2.2 & 4.6 & 9.5 \\
\hline $\mathrm{TiO}_{2}$ & 1.3 & 1.1 & 0.7 & 0.4 & 0.1 & 0.1 & 0.2 & 0.3 & 0.4 \\
\hline $\mathbf{V}_{2} \mathbf{O}_{5}$ & 0 & 0.1 & 0.1 & 0 & 0.1 & 0.1 & 0.1 & 0.1 & 0.2 \\
\hline $\mathrm{Cr}_{2} \mathrm{O}_{3}$ & 0.1 & 0 & 0.1 & 0.1 & 0.1 & 0.3 & 0.2 & 0 & $<0.01$ \\
\hline MnO & 1.5 & 1.5 & 1 & 1.1 & 2 & 1 & 2 & 1.4 & 0.6 \\
\hline $\mathrm{Fe}_{2} \mathrm{O}_{3}$ & 9.6 & 9.8 & 8.9 & 6.5 & 8.6 & 6.7 & 10.8 & 8.3 & 8.4 \\
\hline $\mathrm{Co}_{3} \mathrm{O}_{4}$ & 0 & $<0.01$ & 0 & $<0.01$ & 0 & 0 & 0 & $<0.01$ & $<0.01$ \\
\hline $\mathrm{NiO}$ & 0.1 & 0.1 & 0.1 & 0.1 & 0.1 & 0.1 & 0.1 & $<0.01$ & $<0.01$ \\
\hline $\mathrm{CuO}$ & $<0.01$ & $<0.01$ & $<0.01$ & $<0.01$ & $<0.01$ & $<0.01$ & $<0.01$ & $<0.01$ & 0 \\
\hline $\mathrm{ZnO}$ & 0.1 & 0.1 & 0.1 & 0.1 & 0.1 & 0 & 0.1 & 0.1 & 0.2 \\
\hline $\mathbf{R} \mathbf{b}_{2} \mathbf{O}$ & 0 & 0 & 0 & 0 & 0 & 0 & 0 & 0 & 0 \\
\hline SrO & 0.2 & 0.4 & 0.2 & 0.5 & 0.6 & 0.2 & 0.4 & 0.2 & 0.2 \\
\hline $\mathbf{Y}_{2} \mathrm{O}_{3}$ & 0.1 & 0.1 & 0 & 0.1 & 0.1 & 0 & 0.1 & 0 & 0 \\
\hline $\mathrm{ZrO}_{2}$ & 0 & $<0.01$ & 0 & $<0.01$ & $<0.01$ & 0 & $<0.01$ & $<0.01$ & 0 \\
\hline $\mathrm{Nb}_{2} \mathrm{O}_{5}$ & 0 & 0 & 0 & 0 & $<0.01$ & 0 & 0 & 0 & 0 \\
\hline $\mathrm{MoO}_{3}$ & 0 & 0.1 & 0 & 0 & 0 & 0 & 0 & 0 & 0 \\
\hline $\mathrm{CdO}$ & $<0.01$ & 0 & $<0.01$ & $<0.01$ & 0 & $<0.01$ & $<0.01$ & $<0.01$ & $<0.01$ \\
\hline $\mathrm{Cs}_{2} \mathrm{O}$ & $<0.01$ & $<0.01$ & $<0.01$ & 0 & $<0.01$ & $<0.01$ & $<0.01$ & 0 & $<0.01$ \\
\hline $\mathbf{L a}_{2} \mathrm{O}_{3}$ & 0.4 & 1.4 & 0.8 & 1.2 & 1.3 & 0.2 & 0.5 & 1.4 & 0.3 \\
\hline $\mathrm{CeO}_{2}$ & 0.6 & 2.3 & 1.2 & 2 & 1.7 & 0.3 & 0.9 & 1.8 & 0.4 \\
\hline $\operatorname{Pr}_{6} \mathbf{O}_{11}$ & $<0.01$ & 0.2 & 0.1 & 0.2 & 0.1 & $<0.01$ & 0.1 & 0.1 & $<0.01$ \\
\hline $\mathrm{Nd}_{2} \mathrm{O}_{3}$ & 0.2 & 0.5 & 0.3 & 0.4 & 0.3 & 0.1 & 0.3 & 0.3 & 0.1 \\
\hline $\mathrm{Sm}_{2} \mathrm{O}_{3}$ & $<0.01$ & 0.1 & 0 & 0 & 0.1 & $<0.01$ & 0.1 & 0 & $<0.01$ \\
\hline $\mathbf{E u}_{\mathbf{2}} \mathbf{O}_{3}$ & $<0.01$ & 0 & 0 & $<0.01$ & 0 & $<0.01$ & 0 & $<0.01$ & $<0.01$ \\
\hline $\mathbf{G d}_{2} \mathbf{O}_{3}$ & $<0.01$ & 0 & 0 & 0 & 0 & $<0.01$ & 0.1 & 0 & $<0.01$ \\
\hline $\mathbf{T b}_{4} \mathbf{O}_{7}$ & $<0.01$ & 0 & 0 & $<0.01$ & 0 & $<0.01$ & 0 & 0 & $<0.01$ \\
\hline $\mathbf{E r}_{2} \mathbf{O}_{3}$ & 0 & $<0.01$ & $<0.01$ & $<0.01$ & $<0.01$ & 0 & $<0.01$ & $<0.01$ & 0 \\
\hline PbO & 0.2 & 0.1 & 0.1 & 0.1 & 0 & 0 & 0.1 & 0.1 & 0.1 \\
\hline $\mathrm{ThO}_{2}$ & 0.1 & 0.1 & 0 & 0.1 & 0.2 & 0.1 & 0.3 & 0.1 & 0.1 \\
\hline $\mathbf{U}_{3} \mathbf{O}_{8}$ & $<0.01$ & $<0.01$ & $<0.01$ & $<0.01$ & $<0.01$ & $<0.01$ & $<0.01$ & 0 & 0 \\
\hline $\begin{array}{l}\text { Ateşte } \\
\text { Kayıp }\end{array}$ & 9.6 & 7.6 & 7 & 5.6 & 9.2 & 6.9 & 9.3 & 6.9 & 7.1 \\
\hline
\end{tabular}

*Sondaj numaraları ve alınan örneklerin aralıkları 


\section{Modal mineraloji}

MLA, \% alan (area) ve \% ağırlık (weight) olmak üzere iki farklı yöntemle modal analiz verisi üretmektedir. \% alan yönteminde, her mineralin tarama yapılan alan içerisindeki kapladığı hacim dikkate alınmakta; \% ağırlık yönteminde ise, mineralin \% alan değeri ile yoğunluğu çarpılmakta ve yüzde ağırlığa dönüştürülerek tekrar hesaplanmaktadır.

Örneklere ait ortalama modal mineralojik bileşimler Şekil 3'de verilmiştir. 120B ve 120D kodlu örneklerde barit, florit, Fe-oksit, Th içeren parisit, kfeldispat, kuvars ve biyotit minerallerinin baskın mineraller olduğu görülmektedir. Diğer mineralleri ise; eser miktarlarda apatit, $\mathrm{Ba}-\mathrm{Mn}$ oksit, $\mathrm{Nb}$ içeren rutil, muskovit, kalsit, aktinolit, illit, Sr içeren barit, albit, Mn içeren ilmenit, Al silikat, klorit, ilmenorutil, spinel-kromit, sinçisit, zoizit, $\mathrm{Na} / \mathrm{Fe}-\mathrm{U}$-piroklor, klinoklor, siderit, montmorillonit, dolomit, $\mathrm{Fe}-\mathrm{Mg}$ hidroksit/oksit, talk, kaolinit, $\mathrm{Pb}-\mathrm{Mn}$ oksit, piroksen, pirit, Mn-Fe oksit, ilmenit, turmalin, nefelin, granat, monazit, perovskit, smitsonit, stronsiyanit, enarjit, $\mathrm{Na} / \mathrm{Al}$ fosfat, kalkopirit, Th oksit, vanadyum, filogopit, Al-Sr fosfat, titanit, jips, zirkon, plajiyoklaz, jarosit, spinel-hersinit, galenit ve viterit mineralleri oluşturmaktadır.

$120 \mathrm{E}$ kodlu örnekte barit, florit, kuvars, Fe-oksit, biyotit, Ba-Mn oksit, Th içeren parisit, NTE karbonat ve $\mathrm{Mn}-\mathrm{Fe}$ oksit minerallerinin baskın mineraller olduğu görülmektedir. Diğer mineralleri ise; eser miktarlarda piroksen, k-feldispat, viterit, spinelkromit, $\mathrm{Nb}$ içeren rutil, Al silikat, $\mathrm{Pb}-\mathrm{Mn}$ oksit, aktinolit, kalsit, apatit, muskovit, klorit, albit, pirit, zoizit, illit, stronsiyanit, Al fosfat, ankerit, Al-oksit, $\mathrm{Fe}-\mathrm{Mg}$ hidroksit/oksit, sinçisit, Fe-U-piroklor, kaolinit, ilmenit, monazit, plajiyoklaz, Th oksit ve zirkon mineralleri oluşturmaktadır.

297A kodlu örnekte barit, florit, k-feldispat, Fe oksit, NTE karbonat ve Th içeren parisit minerallerinin baskın mineraller olduğu görülmektedir. Diğer mineralleri ise; Ba-Mn oksit, biyotit, zoizit, $\mathrm{Pb}-\mathrm{Mn}$ oksit, apatit, $\mathrm{Mn}-\mathrm{Fe}$ oksit, $\mathrm{Nb}$ içeren rutil, aktinolit, albit, hornblend, kalsit, kuvars, filogopit, klinoklor, Al-Sr fosfat, plajiyoklaz, titanit, ilmenit, şamozit, pirit, illit, Na-U-piroklor, $\mathrm{Al}$ fosfat, $\mathrm{Al}$ oksit, kaolinit, sinçisit, zirkon, piroksen, montmorillonit, monazit, ankerit, muskovit, plumbopiroklor, kuprit ve tungsten mineralleri oluşturmaktadır.

\section{Hesaplanmış elementel içerik ve elementel dağılım}

Farklı analiz cihazlarında farklı analiz metotları kullanılarak, numunelerin kimyasal içeriklerini belirlemek mümkündür. MLA, modal mineralojik bileşimi ve minerallerin teorik elementel içeriklerini kullanarak, numunenin elementel içeriğini hesaplamaktadır.

$\mathrm{Bu}$ çalışmaya ait hesaplanmış elementel içerik grafiğine bakıldığında, tane boyu küçüldükçe numunelerdeki $\mathrm{Ce}$, $\mathrm{La}$ ve $\mathrm{Th}$ değerlerinin arttığ görülmektedir (Şekil 4A). Ce içerikleri; 120B kodlu örnekte \% 1.6-4.1 aralığında, 120D kodlu örnekte \% 0.7-2.4 aralığında, 120E kodlu örnekte \% 0.8-1.9 aralığında ve 297A kodlu örnekte \% $0.7-3.4$ aralığında değişmektedir. La içerikleri; 120B kodlu örnekte \% 1.2-3.1 aralığında, 120D kodlu örnekte \% 0.5-1.7 aralığında, 120E kodlu örnekte \% 0.5-1.2 aralığında ve 297A kodlu örnekte \% 0.4-2.1 aralığında değişmektedir. Th içerikleri ise; 120B kodlu örnekte \% 0.4-1.1 aralığında, 120D kodlu örnekte \% 0.2-0.6 aralığında, 120E kodlu örnekte \% 0.1-0.2 aralığında ve 297A kodlu örnekte \% 0.1-0.4 aralığında değişmektedir.

Elementel dağılım, hesaplanmış elementel içerik değerlerinin hangi mineral/lerden kaynaklı olduğunun yüzde olarak göstergesidir. Hesaplanmasında, modal mineraloji ve teorik mineral bileşimleri kullanılmaktadır.

Ce ve La için oluşturulmuş elementel dağılım grafiklerine bakıldığında; Ce ve La elementlerinin, 120B kodlu örnekte başlica Th içeren parisit, eser miktarda sinçisit ve monazit; 120D kodlu örnekte başlıca Th içeren parisit, eser miktarda monazit; 120 E ve 297A kodlu örneklerde başlica Th içeren parisit ve NTE karbonat, eser miktarlarda da monazit ve sinçisit mineral kaynaklı olduğu görülmektedir (Şekil 4B). Th için oluşturulmuş elementel dağ 1 lım grafiğine bakıldığında; toryumun, 120B kodlu örnekte başlica parisit, eser miktarda Na-U-piroklor; 120D kodlu örnekte başlıca parisit, eser miktarda Th oksit ve Na-U-piroklor; 120 E kodlu örnekte başlıca parisit, eser miktarda Th oksit; 297A kodlu örnekte başlica parisit, eser miktarda Na-U-piroklor mineral kaynaklı olduğu görülmektedir (Şekil 4B). 


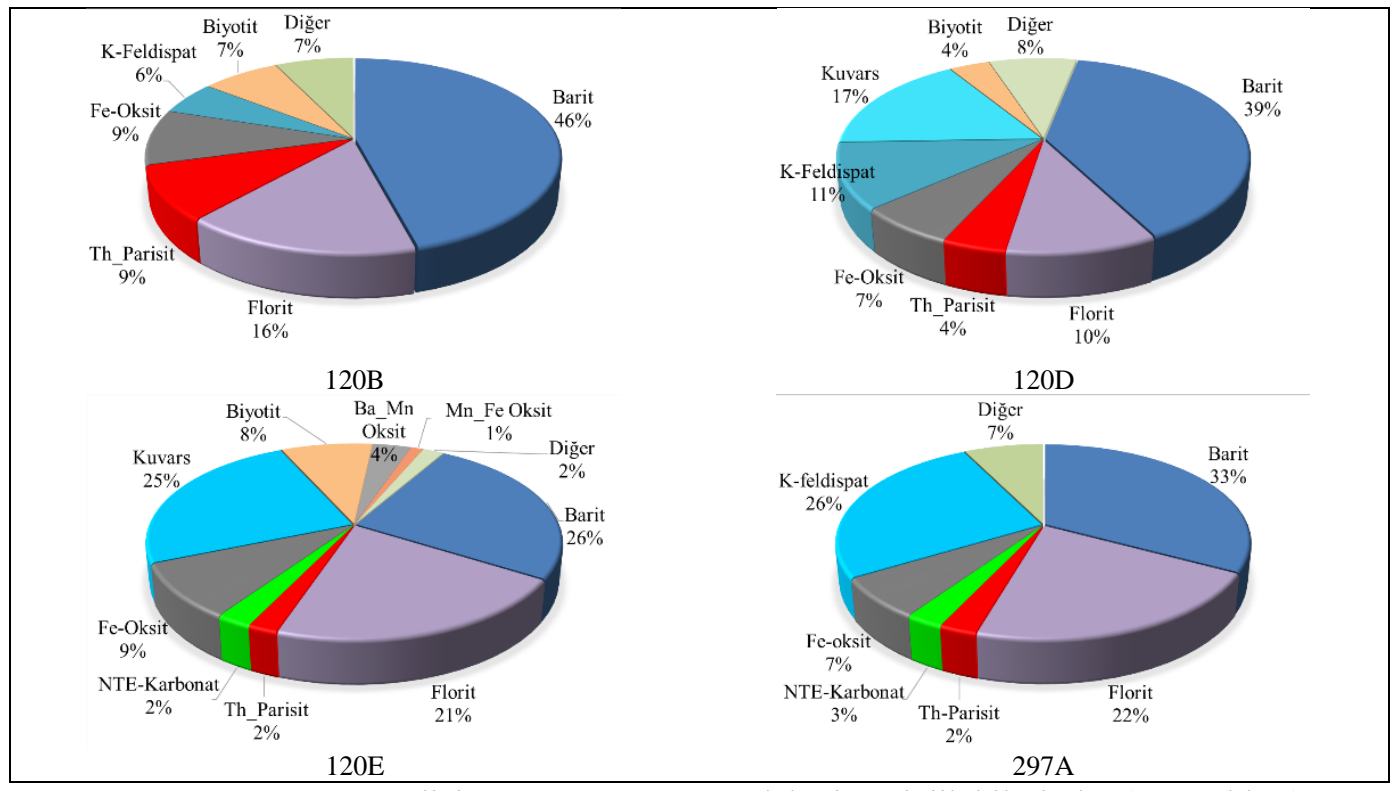

Şekil 3. MLA analizi sonucu saptanan modal mineralojik bileşimler (\% ağırlıkça)

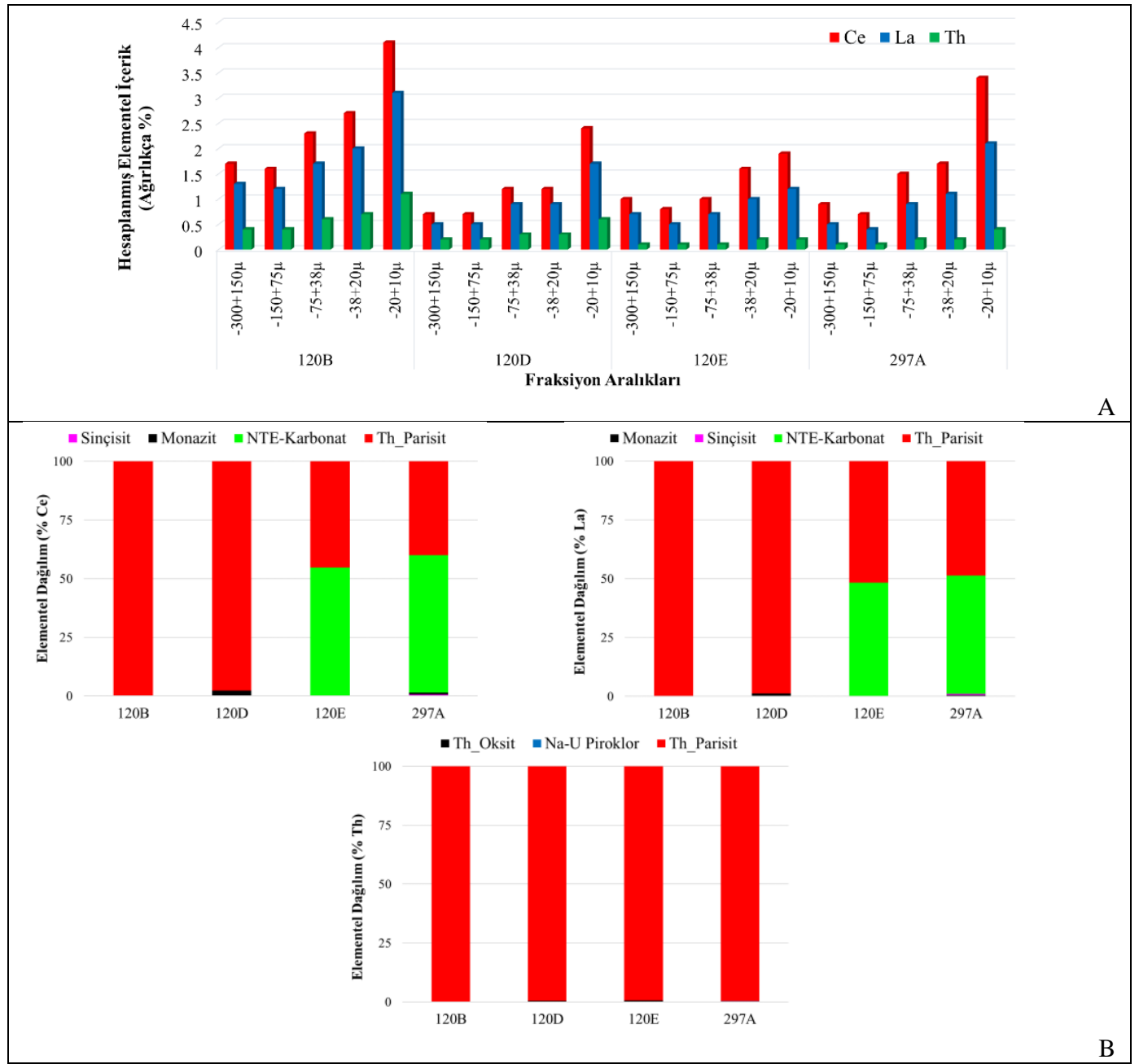

Şekil 4. Ce, La ve Th için oluşturulmuş (A) Hesaplanmış elementel içerik ve (B) Elementel dağı̆ım diyagramları 258 


\section{Çalışma bölgesine ait NTE ve iz element içeren mineraller}

MLA analizleri sonucunda, çalışma bölgesi içerisinde saptanan ana NTE minerali Th içeren parisit olup, az oranlarda diğer NTE ve iz element içeren mineraller tespit edilmiştir (Tablo 2).

Parisit $\quad\left(\mathrm{Ca}(\mathrm{Ce}, \mathrm{La})_{2}(\mathrm{Th})\left(\mathrm{CO}_{3}\right) \mathrm{F}_{2}\right), \quad \mathrm{Ca}$ içeren HNTE'ce zengin bir NTE florokarbonat mineralidir. Çalışma bölgesinde görülen Th içeren Parisit mineralleri, düzensiz şekilli olup, yer yer agrega yer yer de iğnemsi şekilli kristaller halindedir. Mineral, 120B ve 120D kodlu örneklerde büyük oranda florit ve barit; 120E kodlu örnekte büyük oranda florit, daha az oranda da barit ve NTE karbonat; 297A kodlu örnekte ise büyük oranda barit, florit, NTE karbonat, az oranda da Fe-oksit ve diğer mineraller ile birliktelik oluşturmaktadır (Şekil 5A, 6A). Çalışma bölgesindeki parisit mineralleri ağırlıkça yaklaşık \% $27 \mathrm{Ce}, \% 21 \mathrm{La}, \% 8 \mathrm{Ca}$ ve $\% 7 \mathrm{Th}$ içermektedir. Ayrıca yaklaşık \% $11 \mathrm{Nd}, \% 3 \mathrm{Sr}$ içeren parisit mineralleri de tespit edilmiştir (Şekil 5A).

Parisitin serbestleşme derecesi, mineral birliktelik diyagramı ile uyumluluk göstermekte olup, bütün örneklerde beklenildiği şekilde tane boyu küçüldükçe artmaktadır (Şekil 6B). Serbestleşme derecesi iri boyutlarda yaklaşı \% 3-41 arasında değişirken, en küçük boyutlarda \% 41-77 arasında değişmektedir.
NTE karbonat mineralleri $\left.(\mathrm{Ce}, \mathrm{La})\left(\mathrm{CO}_{3}\right) \mathrm{F}\right)$, parisit ve sinçisitten farklı olarak masif, tanesel șekilli kristaller halindedir. Mineral ağırlıkça yaklaşık \% 30-35 Ce, \% 17-19 La, \% 4-15 Nd ve \% 0-5 Ca içermekte olup, bazılarının ağırlıç̧a yaklaşık \% 2 Y, \% $3 \mathrm{Sr}, \% 2 \mathrm{Th}$ ve \% 4 Pr içerdiği de saptanmıştır (Şekil 5B). Parisitle kıyaslandığında Ce değerlerinin yükseldiği, $\mathrm{Ca}$ ve Th değerlerinin ise düştüğü tespit edilmiştir. NTE karbonat mineralleri, Nikiforov vd. (2014) tarafindan HNTE florokarbonatlar olarak adlandırılmıştır. Araştırıcılar tarafindan; NTE ile Th, Ca ve Sr [2NTE $\rightarrow \mathrm{Th}+(\mathrm{Ca}, \mathrm{Sr})]$ arasındaki yer değiştirme dikkate alınarak, sözü edilen minerallerin parisit-bastnazit arası bir kimyasal bileşime sahip olduğu ifade edilmiștir.

NTE karbonatlar ikili ve çoklu kenetliliği çoğunlukla, değişen oranlarda barit, Fe/Ba-Mn oksit, Th içeren parisit ve floritle yapmaktadır.

Sinçisit $\left.(\mathrm{Ce}, \mathrm{La}) \mathrm{Ca}\left(\mathrm{CO}_{3}\right)_{2} \mathrm{~F}\right)$, parasite benzer bir kristal formuna ve kimyasal bileşime sahiptir. Çalışma bölgesinde saptanmış olan sinçisit, parisite göre miktarca oldukça azdır. La ve $\mathrm{Ca}$ içerikleri dikkate alınarak parisitlerden ayırt edilmiştir. Çalışma bölgesindeki sinçisit mineralleri ağırlıkça yaklaşı \% $21 \mathrm{Ce}, \% 15 \mathrm{Ca}$ içermektedir (Şekil 5C). Mineral ikili ve çoklu kenetliliği çoğunlukla, değişen oranlarda barit, florit, Th içeren parisit, NTE karbonat ve $\mathrm{Fe} / \mathrm{Ba}-\mathrm{Mn}$ oksitlerle yapmaktadır.

Tablo 2. Çalışma bölgesi içerisinde saptanan NTE ve iz element içeren mineraller

\begin{tabular}{|c|c|c|c|c|c|c|}
\hline & \multirow{2}{*}{ Mineral } & \multirow{2}{*}{ Kimyasal Formül** } & \multicolumn{4}{|c|}{ Modal Mineralojik Oran $(\%)^{* *}$} \\
\hline & & & 120B & $120 \mathrm{D}$ & $120 \mathrm{E}$ & $297 \mathrm{~A}$ \\
\hline \multirow{4}{*}{ 四离离 } & Th içeren parisit & $\mathrm{Ca}(\mathrm{Ce}, \mathrm{La})_{2}(\mathrm{Th})\left(\mathrm{CO}_{3}\right) \mathrm{F}_{2}$ & 9.2 & 4.3 & 2 & 2.5 \\
\hline & Sinçisit & $(\mathrm{Ce}, \mathrm{La}) \mathrm{Ca}\left(\mathrm{CO}_{3}\right)_{2} \mathrm{~F}$ & $<0.1$ & - & $<0.1$ & $<0.1$ \\
\hline & Monazit & $(\mathrm{Ce}, \mathrm{La}, \mathrm{Nd})\left(\mathrm{PO}_{4}\right)$ & - & 0.1 & $<0.1$ & \\
\hline & NTE karbonat & $(\mathrm{Ce}, \mathrm{La})\left(\mathrm{CO}_{3}\right) \mathrm{F}$ & - & - & 2.4 & 2.5 \\
\hline \multirow{8}{*}{ 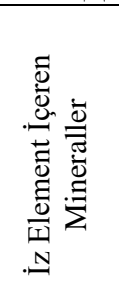 } & $\mathrm{Nb}$ içeren rutil & $(\mathrm{Ti}, \mathrm{Nb}, \mathrm{Fe}) \mathrm{O}_{2}$ & 1.4 & 0.6 & $<0.1$ & $<0.1$ \\
\hline & Strontianit & $\mathrm{Sr}\left(\mathrm{CO}_{3}\right)$ & $<0.1$ & $<0.1$ & $<0.1$ & - \\
\hline & Piroklor & $(\mathrm{Ca}, \mathrm{U}, \mathrm{Na}, \mathrm{Sr}, \mathrm{Th})_{2}(\mathrm{Nb}, \mathrm{Ta}, \mathrm{Fe}, \mathrm{Ti})_{2} \mathrm{O}_{6}(\mathrm{O}, \mathrm{OH})$ & $<0.1$ & $<0.1$ & $<0.1$ & $<0.1$ \\
\hline & Plumbopiroklor & $(\mathrm{Pb}, U, \mathrm{Ca}, \mathrm{Y})_{2} \mathrm{Nb}_{2} \mathrm{O}_{6}(\mathrm{OH})$ & - & - & - & $<0.1$ \\
\hline & Th oksit & $\mathrm{ThO}_{2}$ & - & $<0.1$ & $<0.1$ & - \\
\hline & Al_Sr fosfat & $\mathrm{SrAl}_{3}\left(\mathrm{PO}_{4}\right)_{2}$ & - & $<0.1$ & - & $<0.1$ \\
\hline & Sr içeren barit & $(\mathrm{Ba}, \mathrm{Sr}) \mathrm{SO}_{4}$ & $<0.1$ & - & - & - \\
\hline & Viterit & $\mathrm{BaCO}_{3}$ & - & - & $<0.1$ & - \\
\hline
\end{tabular}

* FEI Standart Reference, FEI Mineral Reference $20 \mathrm{kV}$, FEI Reference STD 25 kV mineral kütüphaneleri ve mineral referans listesinde yer alan kimyasal formüller kullanılmıştır

**Tüm fraksiyonların ortalaması alınmıştır 
DOI: 10.29132/ijpas.907212
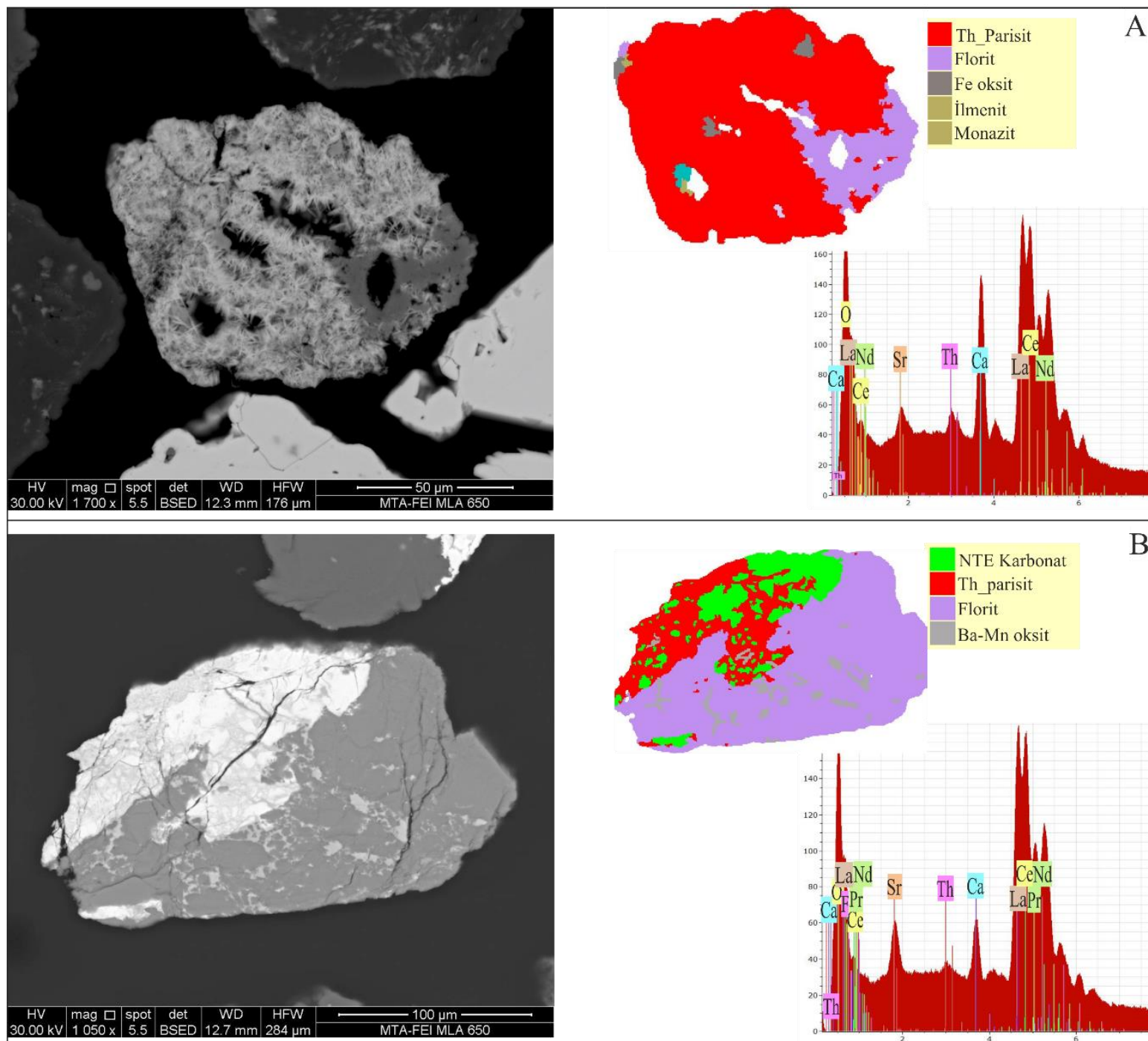

B
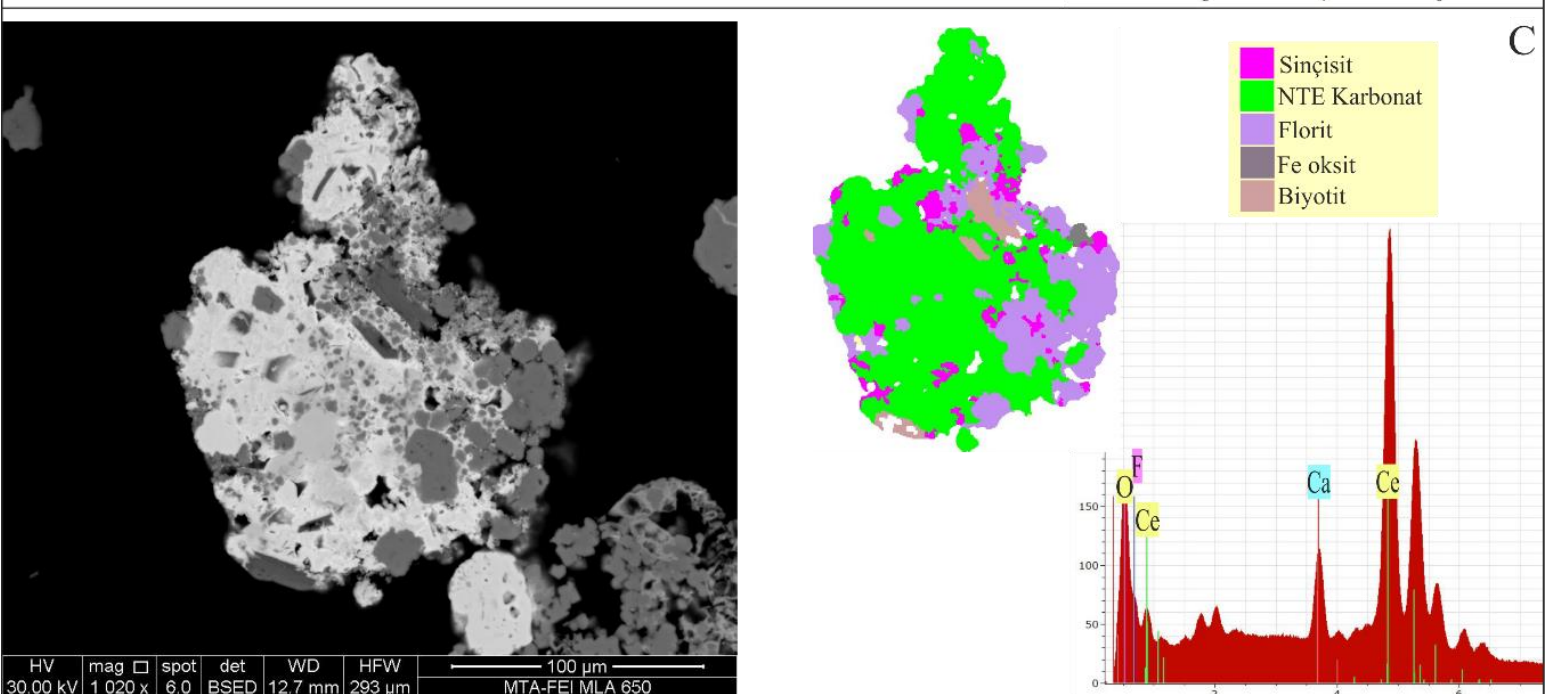

Şekil 5. SEM-BSE, MLA görüntüleri ve EDS spektrumları (A) Th içeren parisit (örnek no: 120B, -300+150 $\mu$ ), (B) NTE karbonat (örnek no:120E, -300+150 $\mu$, (C) Sinçisit (örnek no:297A, $-150+75 \mu$ ) 


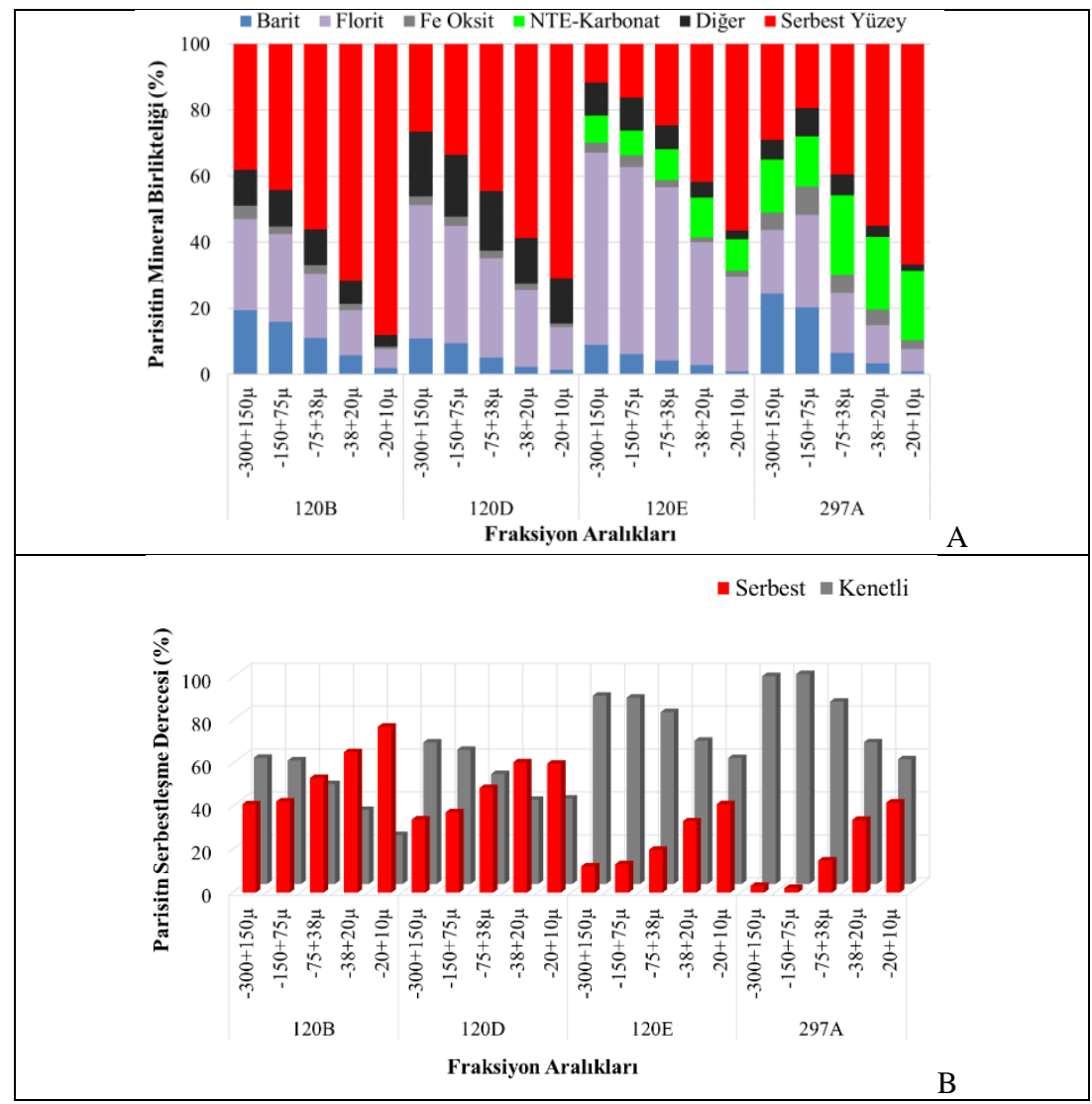

Şekil 6. Th içeren parisitin (A) Mineral birliktelik ve (B) Serbestleşme derecesi diyagramları

\section{TARTIŞMA VE SONUÇLAR}

NTE cevherleşmelerinde çoğunlukla çok aşamalı gelişen jeolojik süreçler, NTE içeren mineral çeşitliliğine yol açmaktadır. Bu durum, NTE içeren minerallerin, klasik analitik metotlarla tayinini zorlaştırmaktadır. Söz konusu sorunun üstesinden gelmek için, minerallerin NTE içeriklerinin dışında $\mathrm{Si}, \mathrm{Ca}, \mathrm{F}$ ve $\mathrm{P}$ içeriklerinin de dikkate alınması gerekmektedir (Schulz vd., 2019).

NTE yataklarında görülen mineral çeşitliliği, teknolojik çalışmalarda da büyük zorluklar ortaya çıkarmaktadır. Bu sebeple, tüm kayaç kimyasının yanında, modal mineraloji, minerallerin kimyasal bileşimleri ve dokusal özellikleri birlikte değerlendirilmelidir. XRF ve ICP (indüktif eşleşmiş plazma) gibi kimyasal analiz yöntemleri ile, sadece tüm kayaç NTE içerikleri saptanabilmektedir. XRD, NTE minerallerinin tanımlanmasına imkan sağlarken, düşük miktardaki minerallerin analizinde belirsizliğe ve hatalara sebep olabilmektedir. Bahsi geçen analitik yöntemler, mineral kimyası, mineral tane boyları, parçacık bileşimleri, mineral iç dokuları ve minerallerin kenetlilik durumları hakkında bilgi vermemektedir.

NTE içeren mineraller, fosfatlar, karbonatlar/florokarbonatlar, halojenler, oksitler, silikatlar ve arsenatlar olmak üzere birçok mineral sınıfında bulunurlar. Ayrıca, minerallerin çoğunda bileşimsel farklılıklar yaygın olup, bir veya birden fazla HNTE, ANTE, Y, Si, Al, Ca, F, P, Nb, Th, U ve benzer elementleri içeren kat1 çözelti serisi oluştururlar (Van Rythoven vd., 2020; Schulz vd., 2019; Bhushan ve Kumar, 2013; Förster, 2001).

Mineraller özellikle kristalografik parametreler (yap1) ve kimyasal bileşimleri dikkate alınarak tanımlanırlar. Ancak, katı çözelti serisi oluşturan NTE içeren minerallerin XRD analiz sonucu ile EDS kimyasal analiz sonuçları uyumluluk göstermeyebilir. $\mathrm{Bu}$ nedenle, kompleks ve benzer bileşime sahip NTE içeren minerallerde, minerallerin element içerikleri ve oranlarının dikkate alındığ 1 , mineralleri kimyasal bileşimlerine göre birbirinden ayırt eden ve fiziksel parametre verilerini üreten, SEM tabanlı otomatik analiz sistemleri kullanılmalı 
ve çalışılan bölgeye özgü özel mineral tanımlamaları yapilmalıdır.

Yapılan bu çalışmada, Kızılcaören kompleks baritflorit-NTE cevherleşmesinde, mineralojik karakterizasyon, ağırlıklı olarak MLA kullanılarak yapılmıştır. Bölgede yapılmış olan önceki çalışmalarda, barit ve floritin yanında baskın NTE minerali olarak bastnazit tespit edilmiştir. Ancak yapılan MLA analizleri sonucunda, bölgedeki baskın NTE mineralleri başlica Th içeren parisit, daha az oranlarda da NTE karbonat, sinçisit ve monazit olarak belirlenmiştir.

Bölgedeki NTE minerallerinin kompleks bir kimyasal bileşime sahip olmaları, klasik analiz metotları ile saptanmalarını zorlaştırmıştır. MLA analizleri sonucunda, NTE minerallerinin değişen oranlarda başlica HNTE (Ce, La, Nd) ve iz element (Th, Sr, Ba) içerdikleri tespit edilmiștir. NTE minerallerinin birbirlerinden ayırt edilmesinde kalsiyumun varlığı ve miktarı önem taşımaktadır. Parisit ve sinçisit, belirgin ve yüksek oranda $\mathrm{Ca}$ içerirken, NTE karbonat minerallerinde çok az oranda Ca tespit edilmiştir. Sözü edilen minerallerde Ce ve La içeriklerinin ve miktarlarının da değişkenlik sunduğu; parisit minerallerinde yüksek $\mathrm{Ce}$ ve La, sinçisit minerallerinde sadece Ce, NTE karbonat minerallerinde de parasite ve sinçisite göre yüksek $\mathrm{Ce}$ içeriği görülmüştür.

NTE içeren minerallerin adlandırılması, NTE dışındaki elementlerin oranlarına göre yapılmıştır. $\mathrm{Ca}$ değerleri yaklaşık \% 7 ve üzeri olan, ayrıca Th içeren mineraller, Th-parisit olarak adlandırılmıştır.

NTE karbonat minerallerinin bünyesinde bulunan $\mathrm{Nd}, \mathrm{Pr}, \mathrm{Y}, \mathrm{Sr}$ ve özellikle Ce ve Ca elementlerindeki değişkenlik adlandırılmalarını zorlaştırmıştır. Ca oranları \% 0-5 arasında değişmekte olup, söz konusu değişkenlik bastnazit-parisit arasındaki bir bileşimi (katı çözelti serisini) ifade etmektedir.

\section{TEŞEKKÜR}

Örneklerin alınması sırasındaki katkılarından dolayı, ETI Maden İşletmeleri Genel Müdürlüğü'nde görevli Jeoloji Mühendisleri Sadık KELEŞOĞLU, Muammer SÖYLEMEZ ve nezdinde Genel Müdürlük çalışanlarına; XRD analizlerinin yapılması ve yorumlanmasındaki katkılarından dolayı, Maden Tetkik ve Arama Genel Müdürlüğü MAT Dairesi Başkanlığ1 Mineraloji Petrografi Araştırmaları Koordinatörlüğü'nde görevli Jeoloji Yüksek Mühendisleri Arif TALAY, Hacer AKORALER ve
Jeoloji Mühendisi Ferhat KARSLI'ya teşekkürlerimizi sunarız.

\section{ÇIKAR ÇATIŞMASI BEYANI}

Yazarlar bu makale ile ilgili herhangi bir çıar çatışması bildirmemektedir.

\section{ARAŞTIRMA VE YAYIN ETİĞİ BEYANI}

Yazarlar bu çalışmanın araştırma ve yayın etiğine uygun olduğunu beyan eder.

\section{KAYNAKLAR}

Arda, O. (1976). Eskişehir-Sivrihisar-Kızılcaören bölgesinde ortaya çıkan toryum ve nadir toprak elementleri içeren karbonatitik oluşumlar ve jenezleri hakkında düşünceler. Maden Tetkik ve Arama Genel Müdürlüğü Teksir, Ankara (basılmamış).

Bingöl, E. (1976). Batı Anadolu'nun jeotektonik evrimi. Maden Tetkik ve Arama Genel Müdürlüğü Dergisi, 86, 14-43. Erişim adresi: https://dergi.mta.gov.tr/

Bhushan, S. K., Kumar, A. (2013). First carbonatite hosted REE deposit from India. Journal Geological Society of India, 81, 41-60. doi:10.1007/s12594-013-0005-y

Castor, S.B., Hedrick, J.B. (2006). Rare Earth Elements. In: Kogel, J.E., Trivedi, N.C., Barker, J.M. ve Krukowski, S.T., Industrial Minerals and Rocks: Commodites, Markets and Uses, $7^{\text {th }}$ edition. SME, 769792.

Çağatay, N. (1981). Türkiye'nin bazı radyoaktif cevherleşmeleri üzerinde mineralojik çalışmalar. Türkiye Jeoloji Kurumu Bülteni, 24, 59-65. Erişim adresi: http://tjb.jmo.org.tr/

Çimen, O., Corcoran, L., Kuebler, C., Simonetti, S. S., Simonetti, A. (2020). Geochemical, stable (O, C, and $\mathrm{B})$ and radiogenic $(\mathrm{Sr}, \mathrm{Nd}, \mathrm{Pb})$ isotopic data from the Eskişehir-Kızılcaören (NW-Anatolia) and the MalatyaKuluncak (E-central Anatolia) F-REE-Th deposits, Turkey: implications for nature of carbonate-hosted mineralization. Turkish Journal of Earth Sciences, 29, 1-17. doi:10.3906/yer-2001-7

Delaloye, M., Özgenç, I. (1983). Petrography and age determinations of the alkaline volcanic rocks and carbonatite of Kızılcaören district, BeylikahırEskişehir, Turkey. Schweizerische Mineralogische und Petrographische Mitteilungen, 63, 289-294. Erişim adresi: volumes?UID $=$ smp-001 https://www.e-periodica.ch/digbib/

Erentöz, C. (1975). 1/500.000 ölçekli Türkiye jeoloji haritası. Maden Tetkik ve Arama Genel Müdürlüğü, Ankara.

Förster, H. J. (2001). Synchysite-(Y) \pm synchysite-(Ce) solid solutions from Markersbach, Erzgebirge, Germany: REE and Th mobility during high-T 
alteration of highly fractionated aluminous A-type granites. Mineralogy and Petrology, 72, 259-280. doi:10.1007/s007100170019

Gültekin, A. H., Örgün, Y. (2000). K1zılcaören (SivrihisarEskişehir) yöresi Tersiyer alkali volkanitlerle ilişkili nadir toprak elementli florit-barit yatakları. Anadolu Üniversitesi Bilim ve Teknoloji Dergisi, 1 (1), 85-94.

Gültekin, A. H., Örgün, Y., Suner, F. (2003). Geology, mineralogy and fluid inclusion data of the Kiz1lcaören fluorite-barite-REE deposit, Eskişehir, Turkey. Journal of Asian Earth Sciences, 21, 365-376. doi:10.1016/S1367-9120(02)00019-6

Gürtekin, G. (2020). Maden atık karakterizasyonunda proses mineralojisi uygulaması. Doktora Tezi, Hacettepe Üniversitesi Fen Bilimleri Enstitüsü, Jeoloji Mühendisliği Anabilim Dalı, Ankara, 427 s.

Kaaden, G. (1966). The significance and distribution of glaucophane rocks in Turkey. Maden Tetkik ve Arama Genel Müdürlüğü Bülteni, 67, 36-37. Erişim adresi: https://dergi.mta.gov.tr/

Kaplan, H. (1977). Eskişehir-Sivrihisar-Kızılcaören köyü yakın güneyi nadir toprak elementleri ve toryum kompleks cevher yatağı. Jeoloji Mühendisliği, 2, 29-34. Erişim adresi: http://tjb.jmo.org.tr/

Kirıkoğlu, S. (1983). Fluorit-baryt-Th und SEElagerstatten in gebbiet von Kizılcaören, Provinz Eskişehir, west-Turkei. Doktorarbeit an der Montanuniversitaet Leoben, 276 p.

Kulaksız, S. (1972). Sivrihisar kuzeybatı yöresinin jeolojisi. Doktora Tezi, Hacettepe Üniversitesi Yerbilimleri Enstitüsü, Ankara.

Kupfahl, H. G. (1954). 55-2, 55-4 (Eskişehir) ve 56-1, 563 (Sivrihisar) paftalarının löveleri esnasında yapılan jeolojik inceleme hakkında rapor. Maden Tetkik ve Arama Genel Müdürlüğü Rapor No. 2247, Ankara (basılmamış). Erişim adresi: https://eticaret.mta. gov.tr/

Möller, P. (1986). Rare Earth Mineral Deposits and their Industrial Importance. In: Möller, P., Cerny, P. and Saupe, F., Lantanides, Tantalum and Niobium. Proceeding of a workshop in Berlin, November 1986, Spring-Verlag. doi:10.1007/978-3-642-87262-4_6

Nakoman, E. (1979). Radyoaktif hammaddeler jeolojisi. Maden Tetkik ve Arama Genel Müdürlüğü Eğitim Servisi, No. 20, Ankara (basılmamış).

Nikiforov, A. V., Öztürk, H., Altuncu, S., Lebedev, V. A. (2014). Kizilcaören ore-bearing complex with carbonatites (Northwestern Anatolia, Turkey): Formation time and mineralogy of rocks. Geology of Ore Deposits, 56 (1), 35-60.

doi:10.1134/S107570151401005X

Özgenç, İ. (1983). Karkın köyü (Sivrihisar-Eskişehir) nadir toprak elementleri florit-barit yatağının incelenmesi. Yayımlanmamış Doçentlik Tezi. Dokuz Eylül Üniversitesi, $131 \mathrm{~s}$.
Özgenç, İ. (1993). Kızılcaören (Sivrihisar-Eskişehir) karbotermal bastnazit-florit-barit yatağının jeolojisi ve nadir toprak element jeokimyası. Türkiye Jeoloji Bülteni, 36, 1-11. Erişim adresi: http://tjb.jmo.org.tr/

Öztürk, H., Hanilçi, N., Altuncu, S., Kasapçı, C. (2019). Rare earth element (REE) resources of Turkey: An overview of their characteristics and origin. Bulletin of the Mineral Research and Exploration, 159, 129-143. Erişim adresi: https://dergi.mta.gov.tr/

Romieux, J. (1942). Sivrihisar, Paşa Dağları ve Emirdağ bölgelerinin jeoloji hakkında rapor. Maden Tetkik ve Arama Genel Müdürlüğü Rapor No. 1431, Ankara (basılmamış).

Samson, I.M., Wood, S.A. (2004). The rare earth elements: behavior in hydrothermal fluids and concentration in hydrothermal mineral deposits, exclusive of alkaline settings. In: Linnen, R.L. ve Samson, I.M. Rareelement geochemistry and mineral deposits. Geological Association of Canada Short Course Notes Volume 17. Geological Association of Canada, 269-298. Erişim adresi: https://gac.ca/product/rare-elementgeochemistry-and-mineral-deposits/

Sayit, K., Göncüoğlu, M. C. (2009). Geochemistry of mafic rocks of the Karakaya complex, Turkey: evidence for plume-involvement in the Palaeotethyan extensional regime during the Middle and Late Triassic. International Journal of Earth Sciences, 98, 157-185. doi:10.1007/s00531-007-0251-6

Schulz, B., Merker, G., Gutzmer, J. (2019). Automated SEM mineral liberation analysis (MLA) with generically labelled EDX spectra in the mineral processing of rare earth element ores. Minerals, 9 (527), 1-18. doi:10.3390/min9090527

Stumpfl, E. F., Kırıkoğlu, M. S. (1985). Fluorite-barite-rare earths deposits at Kizılcaören, Turkey. Mitteilungen Österreichischen Geologischen, 78, 193-200. Erişim adresi: MittGeolGes_78_0193-0200.pdf

Şen, P., Kuşçu, E., Ak, S. (2012). Nadir toprak elementler, özellikleri, cevherleşmeleri ve Türkiye nadir toprak element potansiyeli. Maden Tetkik ve Arama Genel Müdürlüğü Doğal Kaynaklar ve Ekonomi Bülteni, 13, 1-8. Erişim adresi: https://www.mta.gov.tr/ v3.0/hizmetler/dogal-kaynaklar-ve-ekonomi-bulteni

Uçmak, F. (1969). Eskişehir-Sivrihisar-Beylikahır bölgesi toryum cevheri nihai raporu. Maden Tetkik ve Arama Genel Müdürlüğü Radyoaktif Mineraller Servisi, Rapor No. 343, Ankara (basılmamış).

Van Rythoven, A. D., Pfaff, K., Clark, J. G. (2020). Use of QEMSCAN to characterize oxidized REE ore from the Bear Lodge carbonatite, Wyoming, USA. Ore and Energy Resource Geology, 2-3.

doi:10.1016/ j.oreoa.2020.100005

Yakabağı, A. (1977). Eskişehir-Sivrihisar-Kızılcaören köyü yakın güneyi nadir toprak elementleri ve toryum 
kompleks cevher yatağı üzerine 1976 yılında yapılmış çalışmalar hakkında rapor ve Kocadevebağırtan sektörü ile Küçükhöyüklü sektörü rezerv hesabı. Maden Tetkik ve Arama Genel Müdürlüğü Radyoaktif Mineraller Servisi Raporu, Ankara (basılmamış).

Yıldız, N. (2016). Nadir Toprak Elementleri. Maden Mühendisleri Odası, 74 s. Erişim adresi: https://www.jmo.org.tr/resimler/ekler/03cfb3466d7fda f_ek.pdf 